\title{
El Proyecto del Fondo Mundial para la Proteccion del Medio Ambiente (Gef) en Cuatro Areas Naturales Protegidas de Mexico y su Impacto Social ${ }^{1}$
}

\author{
Salomón Nahmad*
}

\section{Introducción}

El presente artículo examina las políticas públicas del gobierno de México durante los últimos cinco años para la conservación y desarrollo sustentable de cuatro regiones indígenas (nahuas, otomíes, mazahuas, lacandones, tzeltales, choles y tzotziles) de los estados de Chiapas, Michoacán, México, Colima, y Jalisco. El gobierno de México se comprometió con el Fondo Mundial para la Protección del Medio Ambiente de realizar acciones tendientes a preparar a las comunidades indígenas para cuidar y proteger la naturaleza. El Banco Mundial ha manejado un fondo especial para estas acciones de los cuales otorgó a México una donación por cerca de 30 millones de dólares en 1996 y es el que ha servido para apoyar la política conservacionista del Instituto Nacional de Ecología en 10 áreas naturales protegidas. Durante nuestra estancia en la oficina para México del Banco Mundial en 1995-1996 pudimos visitar cuatro de éstas áreas y de ellas nos propusimos redactar este artículo con el objeto de visualizar el impacto social de este proyecto y que hoy damos a conocer. Nuestros juicios y nuestras afirmaciones se basan en el trabajo de campo y en la observación participante y directa que reflejan la situación en que se encontraba el proyecto para 1997.

\section{Politicas Publicas Ambientales y Pueblos Indigenas}

Las sociedades occidentales e industrializadas al igual que los pueblos indígenas, dependemos de alimentos obtenidos de plantas y animales, aunque creemos que poseemos algún poder mágico que hace que las plantas crezcan tan abundantemente como deseamos, y que los animales se reúnan en grandes rebaños sumisos a donde quiera que los llevemos, preparados para que los sacrifiquemos

1. Este trabajo fue realizado durante la estancia del año sabático en el Banco Mundial y como Consultor de esta institución.

* Investigador Titular del CIESAS Unidad-Istmo-Oaxaca, México. E-mail: snahmad@ prodigy.net.mx 
según nuestra voluntad. Se puede observar también que construimos ciertos instrumentos manipulando hábilmente bosques, árboles frutales, materiales pétreos, y minerales arrancados del suelo. En una palabra, los indios comprenderían que nosotros utilizamos los recursos de la misma tierra que ellos, que tenemos algunas reglas de conducta similares a las suyas, pero que hemos quebrantado el medio ambiente hasta limites extremos hasta antes no imaginados.

Doscientos años atrás, antes de que se abriese la era de la industrialización, y los descubrimientos tecnológicos, el relativo aislamiento de los pueblos indígenas con sus distintos modos de vida y producción era mucho mayor en su diversidad, y contribuyeron con sus aportaciones a nuestro conocimiento de las variedades de la vida natural, de las costumbres, y de las creencias de la humanidad.

Ni la distribución mundial de las diversas economías, ni su desarrollo e importancia relativa entre pueblos particulares, pueden ser consideradas como simples funciones de las condiciones físicas, y los recursos naturales. Entre el medio ambiente natural, y la actividad humana hay siempre una relación constante, y una serie de objetivos y valores específicos, un cuerpo de conocimientos, y creencias, en otras palabras: un patrón cultural. Pueblos de todos los continentes han fracasado en la realización de descubrimientos que pueden parecer obvios a primera vista. También son importantes las restricciones planteadas por los patrones sociales, y por los conceptos religiosos acerca de la utilización de ciertos recursos naturales, o en las adaptaciones a las condiciones físicas.

Las relaciones entre cultura, y medio ambiente pueden ser directa o indirectamente modificadas por las tecnologías, o las herramientas, utensilios y desde luego por gran parte del patrimonio cultural, y material.

La posesión y transmisión de la tierra y de otras propiedades, el desarrollo y relaciones de las clases sociales, la naturaleza del gobierno, la vida religiosa y ceremonial, son partes de la estructura social, cuyo desarrollo está condicionado, no sólo por los principios de la relación con el medio ambiente, el hábitat y la economía, sino por las complejas interacciones dentro de su propia estructura y por los contactos con el exterior, a menudo totalmente indiferentes tanto al medio ambiente físico como a la economía básica de los pueblos indígenas.

La enorme supremacía en riqueza y poder físico de que disfruta la civilización occidental, en comparación con las culturas mesoamericanas, ha determinado cambios, e incluso violentos colapsos, en una escala abrumadoramente superior a cuanto sucedió anteriormente. El cambio cultural violento y temporalmente quebrantador, como resultado de una dominación y colonización, no es en modo alguno nada nuevo sin embargo los mecanismos actuales han impactado de manera violenta el manejo de la naturaleza y el medio ambiente. Ahora resulta que a los pueblos originales de esta región se les acusa de ser los causantes del deterioro ambiental.

Del mismo modo que los pueblos indígenas han edificado sus sociedades mediante la inclusión y la adición de nuevos elementos a sus culturas, pueden continuar cambiando en dirección positiva a su propio bienestar o del mismo modo también, por la pérdida de elementos, pueden empobrecerse como ha sucedido en las regiones que hoy están bajo la presión de factores externos y de las cuales analizaremos cuatro microregiones.

Desde el punto de vista de las políticas conservacionistas de una civilización tan dominante y poderosa como la del mundo occidental, es preciso que se observe muy conscientemente los impactos sociales, culturales y ambientales de su influencia, que limite los frentes que invade y que retroceda ante los primeros síntomas de desintegración. No obstante, las buenas intenciones de la presión de organizaciones internacionales, y nacionales los pueblos indígenas no tienen el poder que tienen las fuerzas en conflicto dentro del mundo occidental - gobiernos, comerciantes, terratenientes, plantadores, colonizadores y misioneros - es muy difícil plantear un programa de actuación para que sean los propios pueblos indios quienes deban conservar y cuidar el medio ambiente de sus territorios.

De este modo, la ecología cultural o humana, a diferencia de la ecología general, no se ocupa únicamente de la interacción de las formas de vida en un ecosistema en particular, sino de la forma en la que el hombre por medio de la cultura manipula y modela el ecosistema mismo. Los ecólogos culturales han subrayado el punto de que los diferentes modos de manipular el medio ambiente 
(adaptación no pasiva) han producido diferentes tipos de configuraciones y sistemas culturales. Por supuesto, la mayoría de los ecólogos, tanto generales como culturales, probablemente estarían de acuerdo en que el hombre bien podría acabar borrándose de la faz de la tierra por la forma de actuar del modelo económico mundial de apropiación indiscriminada de los recursos naturales. Los pueblos indios y los campesinos de México son los menos culpables del enorme deterioro de los territorios ocupados por ellos como selvas, ríos, montañas, etc.

En este contexto analítico y teórico el Fondo Mundial para la Protección de la Naturaleza (GEF), promovido por Naciones Unidas han apoyado al Gobierno de México para proteger y estimular la sustentabilidad en 10 áreas naturales protegidas que se encuentran en territorios indígenas en distintos estados de la República (Véase mapa localizando las regiones). En este artículo revisamos los aspectos de tipo general que están orientados a cumplir con los acuerdos para operar el GEF, tales como la amplia participación social de los beneficiarios, tratando con ello de construir una relación democrática y participativa de los pueblos indígenas y rurales. Los aspectos técnicos y científicos de las características de la fauna y de la flora pasan a un segundo término para focalizar la atención en la población que vive dentro de los núcleos de las áreas naturales protegidas o en la zona de amortiguamiento. El mayor esfuerzo esta dedicado a capacitar a esta población y orientarla en la construcción de una filosofía y ética de la conservación de la naturaleza.

Lograr mitigar los conflictos agrarios, políticos y económicos de las comunidades, y ejidos es el tema central del trabajo cotidiano de los equipos de cada área protegida que visitamos, las cuales ofrecen un panorama complejo y amplio de problemas sociales que requieren un análisis cuidadoso y reflexivo. Las acciones tendientes a preservar el medio ambiente y la naturaleza que no incluyan el análisis social y político en que viven las comunidades y sus habitantes, tienden a hacer muy difícil el trabajo de la protección del medio ambiente.

Desde el punto de vista de los técnicos de cada área protegida los objetivos parecen ser claros y precisos, pero considerando que la acción no es sobre la naturaleza misma sino sobre la relación hombre-comunidad-naturaleza y dado que en cada proyecto los aspectos sociales y culturales de las comunidades y ejidos no han sido incluidas ampliamente para que los dueños directos del territorio se puedan apropiar de los proyectos y hagan suyos los objetivos de preservación ambiental sustentable. Tratar de modificar y convertir en acciones cotidianas y culturales que disminuyan el impacto sobre el medio ambiente y preserven la biodiversidad al mismo tiempo que logren un desarrollo sustentable que reduzca la pobreza e incremente la producción, es el reto mayor que requiere de tiempos largos dentro de los programas gubernamentales que no los pueden mantener por los cambios políticos constantes y por el bajo perfil y nivel de participación que se otorga a los pueblos indígenas.

\section{Mexico y sus Reformas: Las Utopías para Modificar la Relación entre el Hombre y la Naturaleza.}

Las reformas macroeconómicas, agrarias y ambientalistas que se han venido implementado en México, se dice que tienen como objetivo sostener el crecimiento económico, elevar los niveles de vida de la población y combatir la pobreza, así como reconocer y asumir la responsabilidad de aprovechar de manera distinta los recursos naturales y la obligación de proteger y preservar el medio ambiente, desde una perspectiva de sustentabilidad. Sin embargo, la industrialización subordinó el desarrollo de las demás actividades económicas, particularmente las del sector campesino e indígena y generó un modelo de explotación intensiva y extensiva de los recursos naturales, así como un desarrollo urbano-industrial que no previó sus efectos ambientales ni reguló adecuadamente sus resultados.

En México se reformaron las leyes que regulan la tenencia de la tierra en el medio rural y la explotación y aprovechamiento de los recursos forestales, buscando una mayor responsabilidad de los propietarios de estos recursos en el aprovechamiento económico de los mismos, así como en su 
manejo y conservación. Sin embargo, los resultados no han tenido el éxito esperado y dominan las fuerzas económicas y políticas de las regiones y de los estados que tienden a empobrecer el medio ambiente y a las comunidades.

Se espera utópicamente que independientemente del grado de desarrollo, todas las sociedades deban hacer todo lo que esté a su alcance para mejorar la calidad del ambiente, en función de sus capacidades específicas. Sin embargo las políticas ambientalistas están cargando la responsabilidad en los pueblos indígenas por perturbar el medio ambiente cuando es el sector industrial el que más presiona sobre los recursos naturales de las regiones interétnicas.

En los documentos oficiales las agencias gubernamentales plantean fomentar la corresponsabilidad y la participación social. Orientan su trabajo en varias vertientes a desarrollar una gestión más plural, participativa y con estricto apego a derecho; establecer mecanismos eficientes para procesar consensos entre autoridades y grupos sociales en el diseño de estrategias y políticas; informar a la sociedad de manera constante y transparente; e incorporar nuevos enfoques y prácticas de negociación para resolver los conflictos. Sin embargo, los resultados observados en campo no muestran avances.

\section{Diversidad Biologica y Areas Naturales Protegidas}

México es uno de los países con mayor cantidad de sistemas ecológicos y biodiversidad en su territorio. La vegetación natural, como expresión sintética de todos los factores ambientales, se ha desarrollado a través de casi todas sus posibilidades: desde selvas perennifolias hasta desiertos.

Para proteger esta riqueza, en 1992 se creó la Comisión Nacional para el Conocimiento y Uso de la Biodiversidad (CONABIO), con el objeto de coordinar y promover las acciones y estudios realizados para conocimiento, preservación y uso sustentable. Entre sus funciones están: compilar, mantener y actualizar inventarios de las especies vivas que se encuentran en el país, crear las bases de datos correspondientes para proporcionar un servicio público de información y difusión.

CONABIO participa en la ejecución de programas de cooperación en el marco del Comité Conjunto México-Estados Unidos de América para la Conservación de la Vida Silvestre y en el Comité Tripartita México-Canadá-Estados Unidos de América para el desarrollo de estrategias de conservación.

Las áreas naturales protegidas son un instrumento de la política gubernamental para la protección de la biodiversidad y el mantenimiento de un gran número de funciones ambientales vitales. Por ello, se ha incrementado la superficie que se encuentra formalmente bajo un estatuto de protección (la mayoría en territorios indígenas), promoviéndose la importancia ecológica, social y económica de estas áreas, como sitios propicios para el crecimiento regional sustentable, en beneficio de las poblaciones que habitan dentro de ellas o en sus zonas de influencia.

TABLE 1. Sistema Nacional de Areas Naturales Protegidas (SINAP)*

\begin{tabular}{ccc}
\hline Categoría & Número & Superficie (ha) \\
$\begin{array}{c}\text { Areas de Protección de } \\
\text { Flora y Fauna }\end{array}$ & 9 & 1660502
\end{tabular}

*Fuente: SEMARNAP, INE 1996. Citado en SEMARNAP: México Hacia el Desarrollo Sustentable, 1996.

La solución de los problemas sociales asociados al manejo y regulación de las áreas protegidas pertenecen a la esfera de lo público, pero se requiere la participación social para enfrentarlos con éxito. A nuestro entender el gobierno central expropia los territorios indígenas para convertirlos en zonas protegidas con el argumento de que el uso y disfrute de estos recursos naturales es de todos, pero se limita el control a los propios pueblos indígenas. 


\section{Areas Naturales Protegidas Estudiadas en este Articulo}

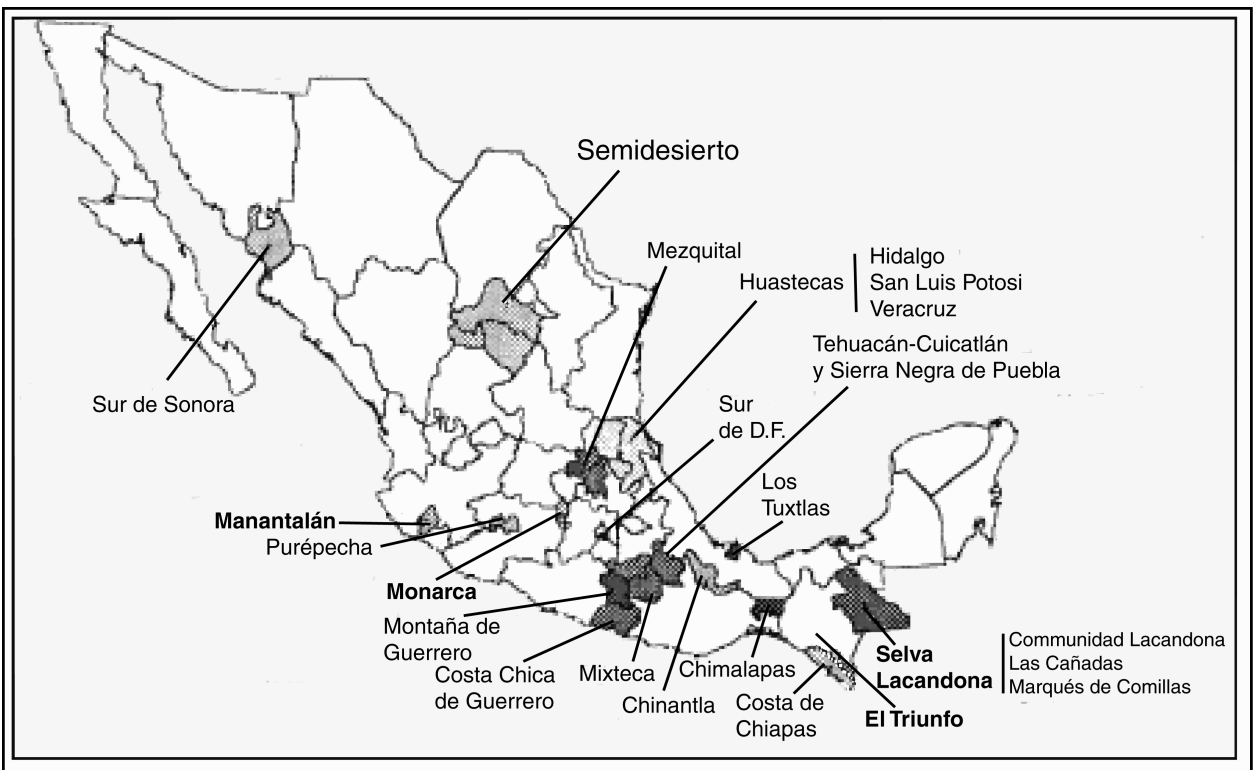

Se complementa el Sistema Nacional de Areas Naturales Protegidas con aquellas áreas que por su biodiversidad, y características sean relevantes, y donde se hayan consolidado programas de manejo, esquemas de financiamiento y mecanismos de participación social.

\section{EI Banco Mundial, Los Pueblos Indigenas y el Medio Ambiente.}

Desde la perspectiva de los analistas sociales del Banco Mundial, han señalado que las experiencias en distintas regiones del mundo han demostrado que a menos que se adopten medidas específicas para los pueblos indígenas, y tribales están más expuestos a ser damnificados que a ser beneficiados en proyectos de desarrollo, focalizados a otros beneficiarios como en el caso de las áreas naturales protegidas que a continuación describiremos.

Una evaluación que realizó el mismo Banco Mundial en los primeros años de la aplicación de esta política (World Bank, 1982), especialmente en proyectos con componentes para la protección de tierras y recursos naturales de los pueblos indígenas, encontró que, a pesar de algunos avances tendientes a lograr una mayor participación indígena en el diseño y ejecución de proyectos, se necesitaba una atención más sistemática a los asuntos legales relativos a la tenencia de la tierra, y que al Banco le faltaba contar con una mayor capacidad profesional para realizar el seguimiento y evaluación de los proyectos que tenían componentes indígenas. Desde esta perspectiva, existen por lo menos varios aspectos íntimamente relacionados que ameritan especial atención. Estos son: 1) la regularización de la tenencia de la tierra y el manejo de recursos naturales, 2) la asistencia técnica y el entrenamiento y capacitación del capital humano, 3) el desarrollo indígena que comienza por reducir el nivel de pobreza y avanza hacia un mayor acceso de la población indígena a bienes y 
servicios, incluyendo a los recursos financieros, y 4) inversiones básicas en educación, salud y otros aspectos del capital humano, adaptados a los pueblos indígenas y sus culturas.

El Banco Mundial ha mostrado una buena disposición para dedicar recursos al fortalecimiento institucional a través de la capacitación de pueblos indígenas así como también para financiar directamente proyectos o componentes de proyectos con los pueblos indígenas. La estrategia está orientada a trabajar con organizaciones indígenas y gobiernos nacionales interesados, apoyando a comunidades y agrupaciones indígenas que deseen mejorar su capacidad para la identificación de necesidades, selección de prioridades de desarrollo, y formulación de estrategias y propuestas que podrían ser ejecutadas con una combinación de sus propios recursos y apoyo external. Como complemento al entrenamiento y fortalecimiento institucional, se procura buscar posibles fuentes de financiamiento de sus propuestas a nivel nacional e internacional.

El caso del proyecto Forestal Comunitario en México y en Oaxaca con financiamiento del Banco ha tomado como base procesos de diagnóstico y evaluación participativa y consultas amplias sobre el sector forestal indígena en la búsqueda de profundizar el proceso de capacitación técnica e incluir inversiones claves que promuevan la forestería comunitaria y la preservación del medio ambiente, particularmente entre los pueblos indígenas de varias regiones del estado de Oaxaca.

Una de las razones de este nuevo enfoque en la participación local es el fracaso de los enfoques anteriores, caracterizados por el paternalismo, y por su orientación vertical de arriba para abajo. Mucho del trabajo actual del Banco con los pueblos indígenas, como la iniciativa de capacitación indígena, debe ser vista dentro de este contexto más amplio que busca estrategias o modelos de desarrollo, partiendo de los derechos y aspiraciones de las poblaciones y comunidades locales.

Sin embargo estas declaraciones del área social del Banco Mundial distan mucho de las políticas públicas del Gobierno de México, como en el caso de las áreas naturales protegidas que han estado bajo el mismo modelo paternalista y dominante, que a nuestro entender se demuestran en las cuatro áreas protegidas que a continuación analizaremos.

\section{Area Natural Protegida de Montes Azules y Selva Lacan- dona del Estado de Chiapas.}

\section{Acciones de conservación de recursos naturales en la región.}

En 1978, y con el propósito de conservar una de las áreas de selvas tropicales más importantes del mundo, se decretó la Reserva Montes Azules, de 331200 hectáreas (Diario Oficial de la Federación, 1978). De éstas, 283773 hectáreas se ubican dentro del polígono de los Bienes Comunales de la Comunidad Zona Lacandona, es decir, el 85.68 por ciento de la superficie decretada para la reserva. Catorce años después se decretaron, dentro de los Bienes Comunales, cuatro áreas protegidas adicionales, que en conjunto abarcan 81035 hectáreas (Diario Oficial de la Federación, 1992a,b,c,d).

Desde 1991, la Comunidad Zona Lacandona ha estado involucrada en la operación del Programa de Inspección y Vigilancia de la Selva Lacandona. En este programa, algunos mayas lacandones han tenido una fuente de trabajo y capacitación con respecto a la conservación y el manejo de los recursos naturales. Sin embargo su participación no es de empoderamiento y de toma de decisiones.

\section{La importancia ambiental de la Selva Lacandona}

La Selva Lacandona es una de las áreas de mayor importancia en el mundo desde el punto de vista ambiental. Es una de las regiones que mantiene una mayor parte de la biodiversidad de México. Se han registrado hasta la fecha más de 3,500 especies de plantas, 1,157 especies de invertebrados y más de 500 especies de vertebrados. Sin embargo, la biodiversidad potencial puede sobrepasar las 50,000 especies de plantas, hongos y animales. 
El hecho de que la Selva Lacandona constituya un área natural protegida de enormes volúmenes de carbono, le otorga un valor adicional al nivel mundial en lo que respecta al creciente efecto de sobrecalentamiento por la liberación de carbono a la atmósfera. En lo que respecta a su hidrografía, la región lacandona contiene un importante y complejo sistema, que abarca el 53 por ciento de una de las cuencas hidrográficas de mayor trascendencia de México: la del río Usumacinta.

La conservación de la Selva Lacandona es no sólo una prioridad para México, sino para el mundo entero. En un contexto regional, las selvas de la zona Lacandona forman parte de la segunda mayor extensión de bosques tropicales en el continente americano: la Selva Maya, que está conformada por la Selva Lacandona, las selvas del sur de Campeche y Quintana Roo (en México), las selvas del departamento de El Petén de Guatemala y las selvas de Belice. Pese al proceso de deforestación que ha ido afectando a la Selva Maya, es todavía la mayor selva de Mesoamérica y, después de la Selva Amazónica, la segunda en extensión en todo el continente americano.

\section{Deforestación}

Se ha estimado que los bosques tropicales de la Selva Lacandona cubrían originalmente una superficie cercana a 1,300 000 hectáreas. Sin embargo, debido a un proceso de explotación forestal masiva, a una colonización anárquica y extensiva, actualmente, la superficie de la Selva Lacandona que mantiene superficies boscosas es menor a las 600,000 hectáreas. En las dos últimas décadas, a pesar de los esfuerzos e inversiones orientados a la conservación de los bosques en esta región, la Selva Lacandona ha estado sujeta a un progresivo proceso de deforestación, que ha afectado la superficie de los Bienes Comunales, incluyendo a las "áreas naturales protegidas", que oficialmente se han establecido para la conservación de la biodiversidad.

\section{Capital ambiental}

Las zonas de los Bienes Comunales que no están dentro de las áreas naturales protegidas y que cuentan hoy en día con selvas, contienen importantes cantidades de recursos forestales (maderables y no maderables) que son, sin duda, un importante capital que debe ser conservado y aprovechado de manera racional para el desarrollo de los hach winik, así como también de los tzeltales y choles que constituyen la Comunidad Zona Lacandona.

\section{Conocimiento del entorno selvático}

Con respecto al conocimiento que los mayas lacandones tienen del entorno selvático, éste ha sido estudiado y documentado por numerosos autores desde diversas perspectivas antropológicas (Nations y Nigh, 1980; Marion, 1991); no obstante, no se ha sabido aprovechar como un acervo del gran valor para el desarrollo de modelos sustentables de aprovechamiento de los recursos naturales en estos complejos ecosistemas.

Esta área natural es la mas critica desde el punto de vista social y político, está habitada por los indígenas lacandones, choles, tzelzales, tzoltziles, tojolabalanes, chinantecos, totonacos, y mestizos de varios estados del país y esta asociada a seis áreas naturales mas que se encuentran en el entorno. Se ha complicado además por la presencia desde hace varias décadas de población originaria de otros estados de la república, o de comunidades del propio estado de Chiapas. También la presencia de organismos académicos como el Instituto de Ecología de la Universidad Nacional Autónoma de México (UNAM), el Colegio de la Frontera Sur (ECOSUR), Instituto para el Desarrollo Sustentable en Mesoamerica A.C., etc., y por otra parte la acción de Organizaciones No Gubernamentales (ONG's) internacionales y nacionales como Conservación Internacional, o el caso de las grandes empresas nacionales como Compañía Tabacalera La Moderna (PULSAR), etc., incluyendo los conflictos políticos por la injerencia activa de diversos partidos políticos y de corrientes ideológicas confrontadas. Aunada a esta intervención externa, el levantamiento armado del Ejército Zapatista de Liberación Nacional en 1994 ha complicado el análisis social con la visión conservacionista, por lo que se requirió de una cuidadosa revisión del fenómeno social y cultural de las comunidades de esta 
área natural. La región cuenta con una área núcleo que no es el punto central de la atención sino los aspectos sociales y políticos los que limitan una participación social amplia, democrática y transparente. La tipología de las comunidades no ha sido bien diagnosticada y analizada y por ello las importantes inversiones que ha realizado el gobierno federal y estatal en la ultima década para detener el deterioro ambiental, no ha tenido el impacto deseado. El conocimiento que tienen los funcionarios del área protegida es excelente desde el punto de vista biológico, pero se complica por el desconocimiento de la interacción social y las acciones politizadas de las agencias gubernamentales federales y estatales responsables del área.

La politización de las comunidades y la guerra interna zapatista en la selva complica toda la acción social por lo que se considera de suma importancia lograr la paz interna en la zona del área protegida para lograr resolver los conflictos políticos, agrarios, económicos y sociales antes de lograr un plan de mediano plazo para el desarrollo sustentable de la región y la eliminación del deterioro del medio ambiente. El Consejo Técnico Asesor (CTA) del área natural protegida funcionó por dos ocasiones, en 1998 de manera poco adecuada y sin la participación amplia de las comunidades, que requerían de reuniones previas con las comunidades y ejidos para colocar toda la información en el lenguaje y vocabulario adecuado a la tipología de las comunidades para que puedan asimilar los contenidos. Posteriormente realizar reuniones con las agencias gubernamentales, académicas y las ONG's para que el dialogo pudiera ser mas consistente y de comprensión para todas las partes. Nos percatamos de que en CTA no participaban el Instituto Nacional de Antropología e Historia (INAH), y el Instituto Nacional Indigenista (INI), para ver los aspectos del desarrollo y los aspectos del turismo arqueológico, ya que la región estaba teniendo un alto crecimiento en la demanda de servicios turísticos. El lenguaje utilizado en las reuniones excluía las lenguas indígenas de la región para poder ser claros y precisos en las determinaciones y en los acuerdos.

Los guardas del área natural protegida pertenecen a las comunidades que forman parte de los bienes comunales de la Lacandona, lo cual ha permitido una menor invasión del área por parte de familias indígenas de los altos de Chiapas, de la zona norte, o de la región del Marques de Comillas. La petición que realizó la comunidad de Nueva Argentina en la primera reunión del CTA confirmó la necesidad de capacitar y preparar profesionales de las comunidades en el campo de la agricultura, la ganadería, los aspectos forestales y biológicos de la Selva. La apertura de un CAMPUS de la Universidad de Chiapas en Ococingo en 1998, pudiera orientarse a estas actividades con el apoyo del Colegio de la Frontera Sur para que los jóvenes indígenas de las comunidades del área natural protegida pudieran recibir becas comprometiéndose a trabajar en su región al término de sus estudios.

De nuestras observaciones en la comunidad de Nueva Argentina desprendimos una conclusión, de que habría que poner mayor énfasis en trabajar con las comunidades no atendidas hasta ahora, como en el caso de las tres comunidades de los bienes comunales lacandones. La respuesta de participación de las comunidades mas aisladas parece ser mas adecuada y con resultados de efectividad a corto plazo. Se sugirió que las autoridades del área natural protegida presentaran un informe de las actividades realizadas en 1997 con las comunidades indígenas de la selva con un señalamiento crítico hacia las propias acciones de los miembros del área protegida, y con una descripción de los aspectos negativos por parte de las comunidades.

La situación agraria en la región sigue siendo un punto central de la crisis general por lo que las acciones desarrolladas por la Secretaría de la Reforma Agraria no han sido lo suficientemente firmes para regularizar la tenencia de la tierra de tal manera que el gobierno federal a través del ejército y el gobierno estatal a través de la policía están usando toda la fuerza pública para resolver el problema de las invasiones de tal manera que en vez de disminuir la tensión social y política esta se ha agudizado con presiones desde el exterior del área natural protegida hacia las comunidades de los bienes comunales lacandones. La protección ambiental por lo tanto resulta una aspiración mas que un logro, pues las tensiones agudizadas fomentan el deterioro de la selva.

Buena parte de los problemas económicos de las comunidades de la zona Lacandona son consecuencia de la falta de organización y recursos financieros para lograr el mejoramiento de la 
producción agrícola y de la comercialización de sus productos. Hoy en día los productores de chile, maíz, miel y otros productos agrícolas y naturales (palma xate, pita) dependen en una gran parte de los intermediarios para poder dar salida a su producción. Estos pagan los productos a precios mínimos y son quienes realmente obtienen las ganancias al hacer llegar estos bienes a los mercados locales y regionales. Con respecto al xate y a la pita es una demanda expresada por parte de varios miembros de la comunidad de que requieren el apoyo necesario para emprender sus propias microempresas y dejar así de depender de los intermediarios y de los bajos precios que éstos pagan por estos productos.

\section{Area Natural Protegida del Triunfo en Chiapas}

\section{Importancia biológica.}

La representatividad biológica de El Triunfo es una de las más altas, no sólo de México sino del mundo entero. Alberga gran variedad de especies de fauna, muchas de ellas endémicas, como el pavón cornudo y la tángara ala-negra, así como especies amenazadas, como el jaguar, el tapir y el mono araña.

El café ha sido tradicionalmente uno de los principales productos de exportación y una de las más importantes entradas de divisas del país. Chiapas es el mayor productor de café de México, y sus cultivos dependen en gran parte de los bosques de niebla como El Triunfo. Su conservación es un reto para todos los mexicanos, no sólo por su importancia biológica, sino porque es prioritario para la economía del estado.

El Triunfo fue declarado Reserva de la Biosfera en 1990, bajo la administración del Instituto de Historia Natural. Sus labores incluyen la investigación, la vigilancia y sobre todo el trabajo con las comunidades aledañas, para desarrollar alternativas de uso sustentable de los recursos naturales.

Enclavada en lo alto de la Sierra Madre de Chiapas, cubierta gran parte del año por una fina niebla, la Reserva de la Biosfera de El Triunfo comprende una superficie de casi 120 mil hectáreas, en donde se encuentran diversos tipos de vegetación, tales como selvas subcaducifolias y subperennifolias, bosques tropicales lluviosos, bosques de pino y de pino-encino-liquidámbar y, en lo más alto de la sierra, el llamado bosque de niebla o bosque mesófilo de montaña, cuya extensión en esta zona es una de la más importantes del país.

Otros factores que influyen determinantemente en el mantenimiento de esta diversidad son la confluencia de dos grandes regiones hidrológicas de Chiapas, la de la costa del Pacífico y la del río Grijalva-Usumacinta, así como los distintos tipos de suelos que ahí se han formado, y que representan una peculiar historia geológica que hizo de este lugar un refugio de vida durante las glaciaciones del Pleistoceno. La conservación de todos estos aspectos es fundamental para la sobrevivencia de la flora y la fauna que ahí habitan.

\section{Amenazas}

Para su protección y manejo, él área natural protegida de El Triunfo está dividida en cinco zonas núcleo, que suman cerca de 25 mil hectáreas, y una gran zona de amortiguamiento de más de 90 hectáreas. El plan de manejo que rige el funcionamiento del área natural estipula que en las zonas núcleo no se permite ninguna actividad productiva o extractiva, ya que su fin es la conservación y la investigación científica. El objetivo de la zona de amortiguamiento es el de proporcionar una protección a las zonas núcleo, estableciendo restricciones y normas en el uso y la extracción de los recursos naturales.

La destrucción de la cubierta vegetal de esta región puede tener serias repercusiones. La humedad procedente del Pacífico y del Golfo de México se condensa al chocar con los bosques de la sierra, y se precipita en forma de lluvia y neblina. Esta inmensa cantidad de agua es captada gracias a la vegetación y es la que alimenta numerosos poblados ubicados en las zonas adyacentes a la 
sierra. El sistema hidroeléctrico del río Grijalba, la producción camaronícola y pesquera de la costa de Chiapas, así como el sistema productivo asentado en ambas vertientes de la sierra, dependen en gran medida de la conservación de la cobertura vegetal que ahí se asienta, ya que es la principal encargada de regular los ciclos atmosféricos que se llevan a cabo en la región.

\section{Importancia económica e historia de la región}

En la región donde se localiza el área natural protegida de El Triunfo se han encontrado restos de actividades humanas de más de 5 mil años de antigüedad, los cuales atestiguan la presencia de grupos de cazadores-recolectores.

El cultivo del café, el más importante en la actualidad, no llegó a la región sino hasta fines del siglo XIX, cuando, estimulados por el Gobierno, algunos inversionistas europeos establecieron las primeras plantaciones. Las condiciones climáticas e hidrológicas imperantes en esta zona, que se dice es la cuna del cacao, resultaron ser igualmente favorables para el nuevo cultivo, por lo que las plantaciones aumentaron en número y tamaño, provocando una fuerte migración de indígenas de Los Altos de Chiapas, Oaxaca y Guatemala.

Actualmente existen en el área natural protegida cerca de 60 ejidos, con mas de 10 mil habitantes y una población flotante considerable, que aumenta con la cosecha del café. La mitad de la población activa se dedica a labores agrícolas (café, maíz y frijol), $15 \%$ vive de la venta de la palma camedora que extraen del monte, y el resto se dedica a actividades como la ganadería y el comercio. El café es un producto clave para la economía mexicana. De su exportación, en 1991 se obtuvieron cerca de 600 millones de dólares, y representó el tercer rubro de entrada de divisas después del petróleo y el turismo. Actualmente, debido a las fluctuaciones del mercado internacional, el precio del café ha bajado considerablemente, pero los analistas prevén su franca recuperación en los próximos años.

La historia de esta área natural protegida se distingue de la lacandona por sus características sociales donde la relación entre quienes iniciaron el trabajo y las comunidades y los pequeños propietarios. El área natural cuenta con varios núcleos que fueron expropiados en 1972 por el gobierno del estado para constituir el área. Estos núcleos constituyen el ejemplo para la preservación de la biodiversidad y para ello la presencia de los guardas nativos del área constituye un capital social invaluable. Consideramos que son ellos los elementos de enlace entre los ejidos, comunidades y propietarios que pueden llevar a largo plazo a la preservación de esta área natural. La creación de esta área natural protegida no fue consultada con los habitantes de la región y se debió a la expropiación del terreno por parte del gobierno estatal lo cual ha generado mucha desinformación y conflictos entre sus habitantes, sin embargo la constitución de una organización de base con siete ejidos denominada Campesinos Ecológicos de la Sierra Madre (CESMACH) promovida desde el Instituto Nacional de Ecología (INE), es un principio de apropiación del proyecto por parte de las comunidades.

El discurso ecologista ha sido adaptado al lenguaje y percepción de los campesinos de origen indígena para incorporarlos a su ideología religiosa y simbólica. El área natural se distingue por estar rodeada en su mayoría por cafeticultores ejidatarios o propietarios, y que tendrían que estar asociados a un proyecto cafetalero para la conservación del medio ambiente y los suelos. La zona produce el café de más alta calidad de México para la exportación y por lo tanto la articulación de la cafeticultura con la conservación ambiental debe ser el eje central del trabajo del área protegida. La desaparición del Instituto Mexicano del Café (IMECAFE), en los años noventa debilitó todo el trabajo con los campesinos cafeticultores y volvió a dejar en manos de los intermediarios y agiotistas la venta y el comercio del café. La variación de los precios del café impactan indirectamente en la preservación del medio ambiente, debido a que si los precios son muy bajos los campesinos e indígenas desmontan parte de la selva para sembrar maíz.

El fondo regional del café y la organización de productores del café no han podido sustituir al IMECAFE. Aun cuando han recibido apoyo de la organización de base de Oaxaca, la Unión de Comunidades Indígenas de la Región del Istmo (UCIRI), de Indígenas Mames de la Sierra Madre 
de Motosintla (ISMAM), productores de café orgánico, y K'nan Choch que significa "Nuestra madre tierra" que son productores de papa y hortalizas; como organizaciones de base no han logrado en esta región consolidar un sistema bien organizado de comunidades. Los conflictos agrarios con las fincas cafetaleras después de 1994 han sido tensas y difíciles. Las condiciones sociales de los trabajadores indígenas guatemaltecos y mexicanos en las fincas son muy negativas y ha afrontado por ejemplo a la comunidad indígena de Santa Rita originarios de Tenejapa (Tzeltales de los altos) con la finca Prusia cuyos propietarios son de ascendencia alemana, habiendo los primeros invadido la propiedad y deteriorado la producción cafetalera y quemado los almacenes. Consideramos que la falta un análisis social y económico de la región permanentemente no ha permitido un trabajo exitoso. Y aunque han entrado en contacto con una ONG, el Instituto para el Desarrollo Sustentable de Mesoamérica, A.C. (IDESMAC) para realizar este trabajo, los resultados fueron de muy bajo perfil.

Los conflictos políticos complican esta situación por la presencia del Partido Revolucionario Institucional (PRI), operado y manejado por las familias de los caciques, y por el Partido de la Revolución Democrática (PRD) que ha movilizado a las comunidades y ejidos.

El área natural de El Triunfo, bajo el mando de los funcionarios con orientación estrictamente conservacionista carecen de la participación social de las comunidades. Las áreas núcleo están altamente protegidas y vigiladas sin embargo existe mucha presión social por la demanda de tierras de las comunidades que tienen un alto grado de crecimiento demográfico.

Existe una investigación y monitoreo de alta calidad en el campo de las ciencias biológicas pero se carece de una investigación de carácter social para entender la relación hombre-naturaleza por lo que se requiere de un diagnóstico social y un asesoramiento sociológico permanente. Las relaciones sociales son tensas y difíciles entre campesinos, indígenas, finqueros, pequeños propietarios y en algunos casos con la misma área protegida.

La presencia del área natural protegida ha impactado a los habitantes de la micro-región por el cambio en el uso de la tierra y la legalización de las áreas núcleo. Los problemas agrarios han tenido que ser atendidos y requieren de la asesoría jurídica para encontrar las vías para su solución. La crisis política agraria del estado de Chiapas se refleja en la región, y los funcionarios del área ocupan gran parte de su energía para evitar que estos conflictos se reviertan negativamente en el medio ambiente. El CTA no fue constituido, y no responde a las distintas microregiones del área como son la costera y la central, pues los problemas que los aquejan son diferentes.

Los planes de desarrollo comunitario dentro del área protegida han sido de muy bajo perfil participativo y no se formuló una tipología que diferencie los distintos orígenes culturales y económicos de las comunidades, ejidos y de los pequeños propietarios para focalizar adecuadamente los programas específicos.

\section{El Area Natural Protegida de la Mariposa Monarca en los Estados de Michoacán y México}

El fenómeno de migración de las mariposas Monarcas ha despertado el interés científico por su conservación durante el presente siglo. Las rutas de viaje y los sitios donde llega a posarse en México quedaron mas o menos delineados y establecidos en 1975 y 1976 por científicos canadienses. A partir de ese momento surge la preocupación por proteger a la mariposa Monarca y su hábitat por parte de un grupo de científicos y de elementos de la sociedad civil, externos a las comunidades campesinas asentadas a la zona. Los biólogos y ecologistas lograron que el Estado de Michoacán decretó en 1980 la zona de hibernación como Zona de Reserva y Refugio de Fauna Silvestre (SUPRIMIDO) sin la opinión de los dueños del territorio otomí y mazahua.

El 9 de octubre de 1986 se creo la Reserva Ecológica de la Mariposa Monarca según Decreto publicado en el Diario Oficial de la federación. La reserva se insertó bajo la categoría de manejo de Reserva de la Biosfera. El área comprende un total de 16,110.14 hectáreas donde se localizan los santuarios de la mariposa y sus áreas aledañas, en la Sierra Chincua, Sierra El Campanario, cerros 
Huacal, Chivati, Pelón y Altamirano. El área natural abarca 38 ejidos, siete comunidades indígenas y 16 propiedades privadas de siete municipios: Donato Guerra, Temascalcingo y Villa de Allende en el Estado de México con una superficie de 7381 hectáreas, y Angangueo, Ocampo, Contepec y Zítácuaro en Michoacán con 8,729.1 hectáreas.

Existen tres zonas núcleo con una superficie dé 4490.51 hectáreas, en donde se localiza el asentamiento anual de las colonias de mariposas, por lo que se declaró la veda total de extracción y uso de la flora y fauna silvestres. Quedan prohibidos los proyectos de obra pública o privada y sólo se permiten tareas de investigación. El resto es zona de amortiguamiento (11 619,53 ha.), en donde se observa también la presencia de mariposas, y está destinada a proteger las zonas núcleo de la contaminación exterior. Aquí, se declara prohibida la caza y el aprovechamiento de especies de flora y fauna amenazadas o en peligro de extinción y las obras son autorizadas por la Secretaría de Estado correspondiente, y la Secretaría de Medio Ambiente, Recursos Naturales y Pesca (SEMARNAP).

$\mathrm{Al}$ tocar el tema del área natural protegida, una de las preguntas que surge inmediatamente es si su creación ha cambiado las formas de uso de los recursos naturales y los sistemas productivos de las comunidades ahí asentadas, así como la dinámica de integración económica de la región al sistema económico dominante. Ambas cuestiones son fundamentales para el logro de la conservación de los recursos regionales y el desarrollo de las comunidades.

La producción económica actual de las comunidades de El Rosario y El Capulín está basada en un sistema productivo que abarca la explotación del bosque, la actividad agrícola y la ganadería de traspatio, sin integración y equilibrio entre ellas, sobre todo en lo que corresponde a la actividad forestal y su relación con la agricultura y la cría de animales.

Ya que hablamos de las alianzas establecidas en la región, que dan pie a la destrucción de los recursos, es necesario mencionar a los actores clave de esas alianzas, mismos que son responsables y beneficiarios directos -mediante la corrupción- de la degradación de los bosques: los funcionarios y los guardias forestales. Estos son los responsables de otorgar los permisos para aprovechamientos forestales, pero poco han tomado en cuenta las restricciones normativas aplicables al área natural protegida, sobre todo por el área forestal del Gobierno, tanto porque sus instituciones se dedican a promover y estimular la producción en el sector primario, como por sus intereses personales.

Todos los hechos descritos hasta ahora influyeron en la degradación de los bosques donde hiberna la Monarca. Según un estudio realizado por una consultaría privada contratada por la Subsecretaría Forestal y de la Fauna de la SARH (1992), entre 1982 y 1990 el número total de hectáreas de bosque degradado en el área de la Reserva fue de 1,563.3 hectáreas, equivalentes a 223.3 ha./año, esto es, una tasa anual del $14.3 \%$, mientras el área completamente deforestada ascendió a 15.1 hectáreas.

Vemos, pues que si bien la actividad forestal es importante para las comunidades otomies y mazahuas la forma en que ésta se realiza da por resultado una explotación irracional del producto y bajos beneficios para los campesinos. El aprovechamiento es llevado a cabo por agentes externos pero también por los mismos campesinos. Estos últimos, a falta de los recursos necesarios para asegurar su subsistencia, permiten a las compañías madereras arrasar los bosques de sus ejidos y se contratan con ellas como taladores. Por otra parte, algunos campesinos talan de manera legal (puesto que cuentan con los permisos correspondientes) o ilegal los bosques, y venden directamente la madera en rollo o "en astillas" a precios muy bajos.

Para tratar de contrarrestar esa situación los campesinos otomies de El Rosario establecieron su propio aserradero a partir de 1991, con objeto de transformar así sea de manera primaria la madera en rollo.

\section{La agricultura}

La otra actividad es la agricultura de temporal dedicada fundamentalmente al autoconsumo. Las parcelas se encuentran dispersas y fraccionadas (minifundio), teniendo en promedio de 1.5 a 2 hectáreas. 
Dentro de la actividad agrícola sobresale también la producción de huertos, ya sean de hortalizas (lechuga, rábano, coliflor) o de frutales (durazno, pera, aguacate y manzana). Se trabajan sin ninguna técnica porque la actividad hortícola no es originaria del lugar, sino que ha sido impulsada por instituciones gubernamentales. Sin embargo, muchas de las verduras producidas no son cortadas, y se pudren porque los campesinos no tienen la costumbre de comerlas y no tienen tampoco medios para su comercialización.

\section{La cría de animales}

La mayoría de los campesinos cría animales domésticos como: cabras, cerdos, gallinas, borregos, caballos y vacas. Éstos tienen mucha importancia para la economía campesina porque funcionan como "colchón de saturated" (ahorro) para tiempos difíciles (enfermedades, muertes, etc.) o cuando hay fiestas familiares (bodas, bautizos, etc.) o de la comunidad (Santo Patrón, Virgen de Guadalupe, etcétera).

Los caballos, burros y bueyes son utilizarlos para ayudar en las labores de los cultivos, para carga y tiro, y son pastoreados en el monte. Por la baja calidad alimenticia del pasto natural tienen poco crecimiento y baja capacidad de reproducción.

Los animales se guardan en corrales sin ninguna planeación y cuando se enferman los medios para curarlos son mínimos, lo que agudiza los efectos nocivos de la mala alimentación.

Todos estos problemas se reflejan en la degradación acelerada de los recursos naturales y en el deterioro de las condiciones de reproducción de la Monarca por los cambios en la densidad del bosque y follaje, en el sotobosque, el suelo y el microclima, así como en bajos ingresos y mala calidad de vida de los campesinos.

El hecho de decretar un área natural protegida sin ninguna relación con los planes de desarrollo estatal y regional, así como sin instrumentar en forma paralela un plan de manejo equilibrado de los recursos en cada comunidad con la participación de los campesinos, no permite frenar sustancialmente la degradación de los recursos naturales. Sigue existiendo una gran presión sobre el uso de los bosques, fundamentalmente en las zonas de amortiguamiento pero también en las zonas núcleo.

La situación anterior ha llevado a plantear el problema de la preservación de la mariposa Monarca y su hábitat bajo la falsa contradicción entre conservación y desarrollo, decretándose en el Estado de México una veda total del bosque, mediante la implantación de un sistema de vigilancia policial en la Reserva por parte del ejército y las dependencias estatales (Probosque, Sedesol, etc.) y planteándose a nivel de ciertos grupos conservacionistas la necesidad de la expropiación o compra por parte de propietarios privados o fundaciones de los santuarios, sin tomar en cuenta a los habitantes indígenas de la zona, acciones que han provocado el aumento de la tala clandestina, la proliferación de incendios provocados y la migración masiva de los campesinos, quienes trasladan el problema de su sobrevivencia del campo a la ciudad, pero sin resolverlo.

En ese sentido se muestra que las acciones de conservación se alejan cada día más e incluso se contraponen al desarrollo, porque el uso de los recursos de los campesinos sigue determinado por decisiones e intereses externos. El desarrollo supone el incremento de la capacidad de intervención de una sociedad y su autogestión, lo que implica que todos los componentes sociales alcancen la posibilidad de definir su propio proyecto de desarrollo o etnodesarrollo y no subordinada al conjunto social externo. Así, situándonos en la perspectiva del interés indígena campesino, el desarrollo estaría ligado al aumento de su poder económico, social y cultural sobre la base de su participación autónoma y del uso racional y sustentable de sus recursos productivos. Esto le permitiría continuar su producción y reproducción social bajo la lógica de la satisfacción de sus propias necesidades y del mejoramiento de su calidad de vida actual. La racionalidad productiva alterna permitiría asegurar también el bienestar de las futuras generaciones. Esto no está sucediendo en la actualidad y la "conservación" ha determinado la pérdida mayor por parte de los campesinos del control de sus recursos y de una forma mejor de vida. 
Un hecho incontrovertible que la conservación del bosque de la mariposa Monarca y en general la biodiversidad de los recursos naturales de la región, solamente será posible si éstos son vistos desde el punto de vista del interés campesino, esto es, como elementos básicos para ayudar a su sobrevivencia e impulsar su desarrollo. En ese sentido es importante citar aquí los planteamientos de seis comunidades, y organizaciones campesinas ubicadas en las selvas tropicales de México: La manera de conservar bosques y selvas es aprovechándolos, no convirtiéndolos en recinto de contemplación para los de fuera, sino en medios de sobrevivencia para los que en ellos viven. La única manera como vamos a poder lograr la conservación y protección de nuestras selvas y bosques, es alentando a la organización campesina para que sean los propios propietarios los que, al derivar beneficio de la selva, se encarguen de cuidarla.

Cuando visitamos él área natural protegida de la Mariposa Monarca pudimos constatar que los técnicos del área han podido delimitar adecuadamente los aspectos que amenazan la conservación de la mariposa y las actividades productivas de las comunidades y ejidos que poseen áreas núcleos o están en el área de amortiguamiento. La participación activa de las comunidades y la información clara y transparente de lo que significa la conservación de la naturaleza ha bajado la tensión social que en años pasados llego a límites extremos. Pudimos participar como observadores del CTA donde asistieron los representantes de las comunidades indígenas, los ejidos y las organizaciones de base tanto del estado de Michoacán como del estado de México en un clima de dialogo y discusión de la problemática de las comunidades en su relación con el aprovechamiento forestal y la conservación de los espacios donde invierna la mariposa Monarca. Un hecho realmente de convencimiento de las comunidades es la presencia de profesionales hijos de ejidatarios y comuneros que han podido explicar al interior de sus comunidades los aspectos positivos de trabajar la tierra cuidando el medio ambiente.

Los funcionarios del área natural protegida han entregado los permisos de aprovechamiento forestal a las comunidades donde ellas han delimitado las áreas núcleo para no ser afectadas las mariposas Monarcas. También las comunidades con la orientación de los miembros del área natural protegida están diseñando los planes para atender al turismo que ha crecido anualmente. Un hecho significativo es tomar en consideración los aspectos culturales para disminuir las críticas negativas de los medios de comunicación, de las ONG's ambientalistas nacionales e internacionales señalando que las comunidades consideran a las mariposas (palomas) como mensajeras de las almas de sus antepasados que vienen a las comunidades precisamente los días de muertos y permanecen hasta la primavera cuando traen el mensaje de iniciar las cosechas al llegar y cuando se alejan el inicio de las siembras. Este hecho singular representa el carácter profundamente místico y religioso de la relación de los indígenas con su entorno ambiental. En general las comunidades se autoadscriben como descendientes de indígenas otomies o mazahuas, y han vivido en relación de largo periodo histórico con la fauna y la flora de su ambiente tal es el caso de la Mariposa Monarca.

Para esta reserva un hecho relevante es la comunicación al interior de las comunidades por la radio del INI y hacia el exterior se recomendó una campaña de información positiva que disminuya la imagen negativa que han creado la televisión y la radio en contra de los indígenas. El trabajo del biólogo, y de los ingenieros forestales y de los guardas de la reserva nos parecieron excelentes por su relación con las comunidades.

El CTA operó fluidamente participando miembros de las organizaciones campesinas de la CNC (PRI) y de las organizaciones del PRD, lo cual permite disminuir las presiones políticas que en el estado de Michoacán son tensas y difíciles. Me pareció que en el CTA próximo deberían asistir las agencias gubernamentales, académicas y las ONG's interesadas en la temática para dialogar con los campesinos e indígenas. Sin embargo esta primera reunión del CTA sin los anteriores actores permitió un diálogo mas fluido de lo cual podemos aprender que se recomiendan reuniones separadas para establecer comunicaciones diferenciadas dentro de los CTAs. 


\section{Area Natural Protegida de la Sierra de Manantlán de los Estados de Jalisco y Colima}

La Reserva de la Biósfera Sierra de Manantlán es un proyecto impulsado por el Instituto Manantlán de Ecología y Conservación de la Biodiversidad (IMECBIO) de la Universidad de Guadalajara, y recientemente incorporado a los programas del Instituto Nacional de Ecología (INE) de la Secretaría del Medio Ambiente, Recursos Naturales y Pesca (SEMARNAP), que se ha considerado como modelo a nivel latinoamericano. La experiencia de casi ocho años de gestión del área natural protegida sirve para ejemplificar los principales problemas que enfrentan los proyectos en los cuáles se pretenden unir los objetivos de conservación de la naturaleza con el desarrollo social, y donde diversos actores, incluyendo instituciones académicas, organizaciones campesinas, grupos de interés y dependencias gubernamentales, generan un ambiente dinámico y complejo de interacciones sociales en torno a la gestión del área.

\section{Descripción de la sierra de Manantlán}

Situada en los límites de los estados de Jalisco y Colima la Reserva de la Biosfera Sierra de Manantlán constituye el área natural protegida más importante del occidente de México por su gran extensión (139 500 ha), alta riqueza de especies silvestres y cultivadas potencial forestal y servicios ecológicos, que presta a toda una región que comprende Colima y el Sur de Jalisco. Sus cuencas son importantes abastecedoras de agua para los valles agrícolas y centros urbanos adyacentes, que albergan una población de más de 400,000 habitantes.

La heterogeneidad ambiental, producto de la variedad de condiciones de relieve, geología, suelos, clima y cubierta vegetal, así como de una marcada influencia humana donde viven los nahuas de Jalisco y Colima, se refleja en una notable riqueza biológica que incluye más de 2,700 especies de plantas vasculares y 560 especies de vertebrados. Los bosques constituyen no solo el hábitat de una gran diversidad de especies de plantas y animales, sino también la fuente productora de agua para una región poblada por unos 400,000 habitantes y un importante recurso para la economía de las comunidades agrarias locales.

\section{El área natural protegida de la Sierra de Manantlán.}

El proyecto de conservación de la Sierra de Manantlán se inició con el descubrimiento de una especie de planta endémica, el teocintle Zea diploperemits, que es un pariente silvestre del maíz cultivado. Esta planta es uno de los ejemplos simbólicos de la importancia de la conservación de especies silvestres por su potencial para resolver necesidades humanas, en este caso, el mejoramiento genérico de variedades de maíz cultivado transfiriendo la resistencia del teocintle a ciertas enfermedades.

El área natural protegida fue creada por decreto federal en marzo de 1987, protegiendo oficialmente 139,500 ha para conservar la biodiversidad y las cuencas hidrográficas, y al mismo tiempo promover un estilo de desarrollo social basado en el aprovechamiento sustentable de los recursos naturales. La Sierra de Manantlán es un área poblada por alrededor de 33,000 personas, 7,000 de ellas viviendo dentro de los límites del área natural protegida, en condiciones caracterizadas mayormente por la pobreza, la marginación y los conflictos agrarios.

El modelo de área natural protegida fue adoptado en la Sierra de Manantlán por tratarse de un área poblada, con importantes valores naturales pero también con agudos problemas sociales y de manejo de recursos naturales y deterioro ecológico. La representatividad de las condiciones de pobreza, presión sobre los recursos naturales, alta biodiversidad, heterogeneidad ambiental y potencial productivo de las zonas de montañas y bosques de México, es justamente lo que hace valioso el experimento de desarrollo y conservación en esta área natural protegida.

Los administradores del área natural protegida nos dicen que: "El manejo debe basarse en la población local. Se reconoce el derecho de los poseedores del territorio del área natural, - 
comunidades, ejidos, propietarios privados- a la autogestión de los recursos naturales para su propio beneficio, pero se enfatiza en el concepto de la "obligación social de la propiedad" que implica hacer un buen uso de los bienes entregados en posesión por la nación según establece la Constitución, no generar daños a terceros, y cuidar el patrimonio natural y cultural.....lo anterior implica una limitación de dominio de los propietarios o poseedores de los terrenos del área natural protegida, en bien del interés público. Por lo tanto, la sociedad en general - de la región de influencia del área natural, del país e incluso internacional - que se beneficia de la conservación de la biodiversidad y los servicios ambientales generados por los ecosistemas forestales, debe contribuir a cubrir los costos de la conservación y a compensar a los pobladores del área natural por las restricciones en el aprovechamiento de los recursos naturales. En otras palabras, la sociedad directamente o a través de las instituciones públicas, debe de contribuir con financiamiento, capacitación, apoyo técnico y servicios a la tarea de la conservación" (Centro Universitario de la Costa Sur). En este sentido sigue siendo muy vertical la definición de participación social en esta área natural.

Para lograr una congruencia en la gestión de un territorio declarado como área natural protegida, pero en el que la unidad de conservación -esto es, el área naatural protegida- está subdividido entre 29 comunidades agrarias y unos 80 predios privados, debe darse a través de un programa de manejo que establece el marco conceptual y normativo y la estrategia general para lograr los objetivos de conservación y desarrollo bajo las propias comunidades. La Dirección del área natural protegida, dependiente del Instituto Nacional de Ecología, en cambio la SEMARNAP, es el agente gubernamental con presencia local y vertical, encargado de la concertación y coordinación de los diferentes actores involucrados en el manejo del área natural protegida, a través de mecanismos teóricamente participativos y con bajo perfil de entrenamiento de los actores sociales.

El territorio donde se estableció esta área natural protegida, había sido escenario de una larga lucha de las comunidades agrarias por la tierra y el control de los recursos naturales, frente a agentes externos, inicialmente las haciendas y luego las compañías madereras y mineras. Hoy el área natural protegida se ha convertido en una nueva figura de la dominación de las comunidades. Para situar en un contexto las condiciones de las comunidades agrarias de la Sierra de Manantlán en relación a los bosques, es necesario hacer una breve reseña de sus características.

Las empresas forestales operaron en las condiciones de economías extractivas o de enclave, generando escasos beneficios en las localidades donde se explotaba la madera, transfiriendo ganancias fuera de estas y dejando un recurso forestal de menor calidad - por ejemplo, bosque jóven en lugar de bosque de viejo crecimiento - incluso severamente degradado.

Las compañías madereras operaron por lo general explotando terrenos que estaban bajo litigios agrarios, donde había solicitudes no resueltas de restitución de bienes comunales o de dotación de ejidos, aprovechando situaciones de aparente indefinición de la tenencia de la tierra. Los madereros aprovecharon la lentitud de los trámites agrarios o incluso interfirieron en estos, para explotar la madera de bosques que aun no tenían una propietario legalmente reconocido. En algunos casos se apropiaron de terrenos privados o de terrenos supuestamente nacionales. El segundo aspecto es que la explotación maderera llevada a cabo en estas condiciones, generó conflictos con las comunidades locales y a lo interno de estas favoreció la corrupción de las autoridades agrarias y la división. Los beneficios económicos para la población local fueron mínimos, ya que incluso la mayoría de los empleados de las compañías madereras venían del estado de Michoacán.

La acción que han realizado algunas ONG's ambientalistas y la Universidad de Guadalajara con su Campus (Centro Universitario de la Costa Sur) en Autlán de Navarro resultan un avance en la conceptualización y en el trabajo de la conservación del medio ambiente. Han logrado permear a las distintas comunidades de la zona del área natural protegida. El trabajo de los Biólogos del área natural protegida se distingue por atender la conservación de la diversidad biológica y en particular la presencia del maíz perenne o maíz teozintle, uno de los mas antiguos maíces de México, al mismo tiempo que su formación en Desarrollo Regional le permite atender los asuntos sociales. El Instituto de Investigación de la Universidad de Guadalajara posee una extensión del área núcleo en propiedad lo que ha permitido servir de modelo a los ejidos y comunidades indígenas para preservar las 40 mil 
hectáreas de las zonas núcleos y las 100 mil restantes del área de amortiguamiento. Han tratado de establecer una relación permanente con las 17 familias de la comunidad de Toxquin que viven dentro del área núcleo pero el resto de la población vive en la zona de amortiguamiento y es la que ejerce mucha presión sobre las zonas núcleo. La Universidad de Guadalajara mantiene un excelente centro de información geográfica, que esta muy orientado hacia la parte ecológica y requiere incluir en esta información geográfica los aspectos de carácter social y cultural. Podríamos considerar que dentro de la investigación y monitoreo del área natural protegida debería incluirse la presencia de los analistas sociales que ayudaran a explicar los distintos fenómenos sociales y políticos que se dan en las comunidades y las tensiones con el Instituto.

La principal actividad que afecta al área natural protegida es la explotación forestal pues la zona no tiene veda y se trata de evitar la explotación de las áreas núcleo. Sin embargo en la zona de amortiguamiento esta actividad es fundamental para la economía de los ejidos y las comunidades. Cuentan con 20 aserraderos en la región y están en contacto con la comunidad indígena tarasca de Nuevo San Juan, Michoacán que tiene la experiencia mas avanzada en asuntos forestales. Sin embargo no cuentan con recursos económicos con la posibilidad de construir un modelo sustentable de aprovechamiento forestal seria la recomendación más importante. Si se lograra expander el proyecto Forestal Comunitario de Oaxaca pudiera experimentarse en esta región de Colima y Jalisco un cambio sustantivo.

Existe una base de personal del área natural protegida que es originaria de la región (12 personas) y 5 que son de fuera. Consideramos que la presencia de la Universidad de Guadalajara debería focalizar su atención en formar los profesionales requeridos de los ejidos y comunidades para que ellos se apropien del proyecto de la conservación del área natural protegida y no cuentan con profesionales en ciencias sociales.

La situación de la comunidad indígena nahua de Ayotitlán que se encuentra en alto grado de erosión y deterioro cultural requiere de una atención especializada dada la dimensión de su población y al mismo tiempo del gran espacio territorial que ocupa dentro del área natural protegida. Pudimos observar al final de una asamblea comunitaria que expresaba el grave conflicto social interno entre sus distintos núcleos de poblacion y la crisis permanente con la compañía minera de Autlán que se encuentra dentro de su territorio y genera tensiones sociales graves que han llevado a violencia y asesinatos dentro de la comunidad. Nos parece relevante trabajar con el Consejo Indígena de Manantlán con el objeto de fortalecer los aspectos de identidad propia que vayan asociados con la preservación ambiental. Lo mismo se puede recomendar para la comunidad de Cutzalapa donde pudimos observar los pequeños proyectos de apicultura, piscicultura y del taller de bordados que a nuestro entender se refieren a acciones muy modestas frente a la enorme demanda de las comunidades.

La visita a la comunidad del Terrero del estado de Colima nos permitió confirmar la importancia de la toma de conciencia por parte de los ejidatarios en relación con la conservación de la naturaleza y la articulación necesaria para el aprovechamiento forestal. Creo que esta comunidad pudiera constituirse en modelo de desarrollo comunitario forestal si se lograran los recursos necesarios. Consideramos que debería incluirse en el programa de desarrollo comunitario un tipo de becas para formar los cuadros profesionales de ejidatarios e indígenas a mediano plazo.

Aún cuando manifiestan que existe diálogo interinstitucional no pudimos constatar el nivel de coordinación institucional mencionado en el Plan de la SEMARNAP en especial con el INI para complementar las acciones y ordenar el trabajo social comunitario. La separación de acciones entre dependencias gubernamentales genera acciones que tienden al clientelismo y no a la búsqueda de soluciones participativas de las propias comunidades como en el caso de Ayotitlán que tiene 30 localidades de origen nahuatl y donde incluso las acciones con la propia SEMARNAP no tienen una coherencia operativa en este caso la Delegación de Jalisco y la Delegación del INI y no coordinan sus acciones con el Director del área natural protegida. Las acciones sobre las artesanías textiles o de cestería requieren de un análisis socioeconómico para no crear expectativas económicas que han sido limitadas por las experiencias en este sentido. De la misma manera la coordinación entre los estados y las Universidades de ambos estados no han llegado a acuerdos de coordinación. 
Con relación al CTA consideramos que los conflictos políticos y sociales tanto del estado de Colima como de Jalisco han limitado su integración. Es muy bajo el diálogo interno con las comunidades, las agencias gubernamentales federales y estatales, las agencias académicas y las organizaciones sociales de base para que establezcan un dialogo que permita clarificar y entender la problemática social de la micro-región del área natural protegida de Manantlán.

\section{Conclusiones}

1) En los últimos años el principal paradigma que ha dominado la disciplina de manejo y administración de las áreas naturales protegidas ha sido la integración de la conservación de la diversidad biológica al desarrollo social sustentable. Este nuevo enfoque ha desplazado a aquellos de corte preservacionista y tiene sus orígenes, a partir de la década de los sesenta, en el desarrollo de algunos parques regionales en Europa, que pretendían no sólo preservar la naturaleza, sino también las culturas tradicionales. Posteriormente, esta concepción fue incorporada al modelo de reservas de la biosfera del programa MAB-UNESCO y a la Estrategia Mundial para la Conservación como una alternativa al fracaso del modelo de parques nacionales norteamericanos, adoptados de manera generalizada por la mayoría de los países del tercer mundo.

2) Este cambio de enfoque fue positivo, ya que las áreas naturales protegidas en países pobres, a diferencia de los parques norteamericanos, no son espacios sin habitantes. Muchas de ellas albergan territorios de comunidades indígenas con un arraigo milenario y proveen importantes recursos a las poblaciones locales. Sin embargo, son escasos los ejemplos de una gestión exitosa que integre la conservación y el desarrollo, ya que la mayoría de los proyectos aún mantienen un fuerte interés sobre los aspectos técnicos biológicos, considerando el área silvestre como una especie de "isla", donde se debe dar una relación armoniosa entre la sociedad y la naturaleza, ubicada en un mar de deterioro ambiental. El contexto cultural, socioeconómico, político, regional y nacional raramente es considerado en las acciones de las cuatro áreas naturales protegidas para la gestión de un desarrollo sustentable.

3) Las áreas naturales protegidas de México enfrentan una fuerte presión sobre sus recursos debido, entre otros factores, a las condiciones de extrema pobreza de sus habitantes que son sus propietarios, la aplicación de políticas de desarrollo incompatibles con la conservación y la falta de respaldo institucional para su autogestión. Abundan las "reservas de papel" que fueron decretadas de manera legal, pero que no tienen una protección efectiva en el terreno, ni un programa establecido para su manejo y vinculación con la población local y mucho menos recursos económicos.

4) De nuestras visitas al campo entrevistamos a los Directores y Funcionarios y empleados de las áreas conociendo directamente y de propia voz sus opiniones acerca del avance de los trabajos realizados durante los últimos 3 años. Pudimos constatar el amplio interés en los asuntos sociales y en los conflictos intercomunitarios o entre el área natural protegida y las comunidades y ejidos. El punto central de las dificultades y amenazas al trabajo de las áreas naturales protegidas es de orden social y por ello gran parte de la energía y el esfuerzo de los miembros del área natural protegida se destina a mitigar estos problemas sin llegar a resolverlos.

5) El otro aspecto de tipo general esta orientado a cumplir con los acuerdos para operar el fondo otorgado por el Global Enviromental Facility (GEF) para lograr una amplia participación social de los beneficiarios, tratando con ello de construir una relación democrática y participativa. Los aspectos técnicos y científicos de las características de la fauna y de la flora pasan a un segundo termino para focalizar la atención en la poblacion que vive dentro de los núcleos del área natural protegida o en la zona de amortiguamiento. El mayor esfuerzo debería estar dedicado a capacitar a esta poblacion y orientarla en la construcción de una filosofía y ética de la conservación de la naturaleza en sus propiedades sociales o individuales. Los talleres y los consejos técnicos asesores pasan la mayor parte del tiempo revisando y discutiendo los principios fundamentales en que se constituyeron las áreas naturales protegidas y en formas burocráticas. Lograr el cambio social al nivel de comunidades, ejidos, pequeños propietarios, y sociedad en general que vive en el entorno de las áreas naturales protegidas es la acción más relevante que no pudimos observar. 
6) Lograr mitigar los conflictos agrarios, políticos y económicos de las comunidades y ejidos yes el tema central del trabajo cotidiano de los equipos de cada área natural protegida que visitamos. Las cuatro ofrecen un panorama complejo y amplio de problemas sociales que requieren un análisis cuidadoso y reflexivo. Las acciones tendientes a preservar el medio ambiente y la naturaleza que no incluyen el análisis social y político en que viven las comunidades y sus habitantes, tienden a ser muy difícil el trabajo y lograr los objetivos de cada área natural protegida. Desde el punto de vista técnico los objetivos conservacionistas son claros y precisos pero para lograrlo el tema central es como impulsar a que las comunidades, ejidos, pequeños propietarios se apropien del proyecto y hagan suyo el discurso y se conviertan en acciones cotidianas para conservar el medio ambiente y la biodiversidad al mismo tiempo que logren un desarrollo sustentable. El reto es muy amplio y requiere de tiempos largos para obtener resultados positivos. La inversión es casi nula en proporción al reto de cada área natural protegida, es mas un discurso ecologista que un programa del fondo.

7) Donde individuos y personas de las comunidades están participando como miembros de los equipos de las áreas naturales protegidas la relación entre las comunidades y los ejecutivos del área natural protegida se vuelven menos tensos y difíciles. Para lograr una participación mas consciente se requiere el fortalecimiento y la capacitación profesional del capital humano de cada comunidad o ejido en el tema de protección ambiental.

8) En las áreas naturales protegidas la crisis económica de los últimos años ha impactado de manera directa en las comunidades pues la producción de café, de ganado, de explotación de los recursos forestales, del maíz, etc., han generado mayor invasión de sus propias áreas boscosas y silvestres. De la misma manera el alto crecimiento demográfico esta influyendo para expander la frontera agrícola sobre las áreas de bosque y selva. La disminución del apoyo crediticio por parte de la Banca Gubernamental o privada ha hecho depender a los campesinos e indígenas de los agiotistas de las ciudades del entorno de las áreas naturales protegidas quienes financian con altos intereses los trabajos agrícolas, pecuarios o forestales y que repercuten en el deterioro ambiental.

9) Los aspectos políticos también han impactado a las comunidades y ejidos. Los partidos políticos han penetrado y dividido a muchas de las comunidades de las áreas naturales protegidas. El análisis de esta situación también ocupa la energía y el esfuerzo. Como en el caso del área natural protegida de Manantlán que durante nuestra visita se encontraba en proceso electoral y ello estaba limitando la acción del CTA. En general recomendamos tener un entrenamiento en asuntos sociales y diagnósticos específicos por sociólogos o antropólogos de cada región. También fue recomendado una interacción con el Sector Académico de Ciencias Sociales de cada estado o región.

\section{Recomendaciones}

- Para lograr una mayor participación social y disminuir las tensiones conflictivas se recomendaron diagnósticos de tipo social en cada una de las áreas naturales protegidas.

- Que los diagnósticos sociales generen una tipología de los campesinos, de los indígenas, de los propietarios, de las Onus, de los académicos y de las agencias gubernamentales que actúan como interlocutores en la preservación del medio ambiente.

- Que los aspectos agrarios de cada área natural protegida tenga el diagnostico y las posibles alternativas de solución interna de las comunidades o externas de las agencias gubernamentales.

- Los ideales de la preservación de la diversidad biológica sean acompañados por la preservación de la diversidad cultural. Este tema es nulo en los programas.

- El convencimiento, la capacitación y el entrenamiento de las comunidades para preservar la naturaleza sean acompañados de un mejoramiento económico y no de un empobrecimiento como sucede actualmente por los ajustes macroeconómicos.

- El proyecto de las áreas naturales protegidas que hoy es parte del INE pueda ser transferido y apropiado por las comunidades, ejidos y pequeños propietarios fortaleciendo el conocimiento y el capital humano de los propietarios originales de las áreas naturales protegidas. 
- Las áreas naturales protegidas deben formular planes junto con las comunidades para largo plazo y tener el capital humano profesional formado de las propias comunidades para preservar la biodiversidad y contar para ello con los recursos financieros.

- También se debe diseñar planificación familiar con las instituciones responsables para disminuir el crecimiento demográfico de las comunidades que están ejerciendo gran presión sobre las áreas naturales protegidas.

- La relación hombre naturaleza debe incluir los aspectos culturales de los actores y propietarios de las comunidades para disminuir los prejuicios en contra de los campesinos e indígenas.

- Para fortalecer el desarrollo regional sustentable deben participar agencias especializadas gubernamentales del estado y de la federación tales como el INI, el INAH, SEDESOL, etc. El papel de la Reforma Agraria es fundamental para resolver los conflictos agrarios.

- Me parece que el proyecto de las áreas naturales protegidas del INE esta enfocado a los aspectos naturales y no esta dirigido hacia un cambio social y cultural de las comunidades, por tanto se requiere de una constante interacción entre los aspectos técnicos y biológicos con los aspectos de carácter social y cultural.

- Se sugiere que se presenten los informes anuales de cada área natural protegida sobre comunidades y desarrollo en términos comprensibles y transparentes a los campesinos e indígenas. En especial un informe sobre los avances del programa de desarrollo social de los pueblos indígenas.

\section{BIBLIOGRAFIA}

Barton Bray David, Irvine Dominique,

1993 Resource and Sanctuary: Indigenous peoples, ancestral rights, andd the Forest of the Americas. Cultural Survival Quarterly, Spring Vol. 17 Number 1, Estados Unidos.

CIRAN/Nuffic, CIKARD, LEAD,

1994 Indigenous Knowledge \& development Monitor. Vol. 2 no. 1. Noruega.

Davis Shelton y Ebbe Katrinka.

1993 Traditional Knowlwedge and Sustainable Development. Proceeding of a conference. Enviromentally Sustainable Development Proceedings Series no. 4. The World Bank, Washington, D. C. Estados Unidos.

Forde, C. Daryll

1966 Hábitat, economía y sociedad: introducción geográfica a la etnología. Colección Libros Tau, Ediciones Oikos-tau, Barcelona, España.

González Alvaro, Vásquez Marco Antonio.

1992 Etnias, desarrollo, recursos y tecnologías en Oaxaca. Colección Oaxaca, CIESAS Gobierno del Estado de Oaxaca, México.

Graf Montero, Sergio, Santana Eduardo, et. al.

1997 La Reserva de la Biósfera Sierra de Manantlán: un balance de ocho años de gestión. Revista Universidad de Guadalajara, México.

Grammont, Hubert Carton de

1995 Globalización, deterioro ambiental y reorganización social en el campo. Juan Pablos Editor - UNAM, México.

Hoebel E. Adamson y Weaver Thomas

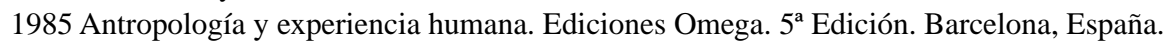

Instituto de Historia Natural,

1992 Bosque de Niebla: El Triunfo. Sierra Madre, Unidos para la Conservación, Instituto de Historia Natural, México.

Instituto Nacional de Ecología.

1997 Programa de Manejo de la Reserva de la Biosfera Sierra de Manantlán: Puntos básicos del documento para consulta. Secretaría de Medio Ambiente, Recursos Naturales y Pesca, Instituto Nacional de Ecología. Elaborado por el Instituto Manantlán de Ecología y 
Conservación de la Biodiversidad, Centro Universitario de la Costa Sur. Universidad de Guadalajara, Jalisco, México.

Jardel P. Enrique, Cruz Gerardo, Graf M. Sergio

1997 Manejo forestal comunitario en una reserva de la biósfera: la experiencia del ejido el terrero en la sierra de Manantlán. XX Congreso Internacional LASA, Guadalajara, México.

Kaplan David y Manners Robert A.

1979 Introducción crítica a la teoría antropológica. Editorial Nueva Imagen. México.

Marion, M. O.

1991 Los hombres de la selva, un estudio de tecnología cultural en medio selvático. Instituto Nacional de Antropología e Historia (INAH), Col. Regiones de México, D.F., 287 pp.

Matías A., Marcos

$1996 \mathrm{El}$ oro, el petróleo y otros recursos estratégicos en las regiones indígenas de México. Ponencia. México.

Marquette Catherine

1996 Prospectus for Producing a Package of information tools on indigenous people and biodiversity in Latin America. The World Bank, Washington. Estados Unidos.

Nahmad Salomón, González Alvaro y Vásquez Marco A.

1993 Medio ambiente y tecnologías indígenas en el Sur de Oaxaca. Centro de Ecología y Desarrollo. México.

Nahmad Salomón, González Alvaro y Rees Martha.

1988 Tecnologías indígenas y medio ambiente: análisis crítico en cinco regiones etnicas. Centro de Ecodesarrollo. México.

Nations, J.D. y R.B. Nigh.

1980 The evolutionary potential of lacandon maya sustained-yield tropical rain forest agriculture. J. of Anthropol. Research. 36 (1): 1-33

Partridge Williams, Uquillas Jorge y Johns Kathryn.

1996 Inclusión de los excluidos: el etnodesarrollo en América Latina. Segunda Conferencia

Anual de Banco Mundial para el Desarrollo en América Latina y el Caribe. Bogotá Colombia.

Toledo Víctor M.

Greening Zapata: Indigenous struggles of ecological inspiration in Mexico. México.

Uquillas Jorge y Davis Shelton

1998 El Banco Mundial y los pueblos indígenas de América Latina. Banco Mundial. Artículo preparado para el libro Pueblos Indígenas y Organizaciones Internacionales, a ser publicado por el Subcomité de Derechos Humanos del Parlamento Europeo.

Uquillas Jorge y Rivera Jean-Carlo

1993 Pueblos indígenas y desarrollo en América Latina. Memorias del Segundo Taller InterInstitucional sobre Pueblos Indígenas y Desarrollo en América Latina. Nota de divulgación no. 8. Banco Mundial. Washington, D. C. Estados Unidos.

Secretaría de Gobernación.

1978 Diario Oficial de la Federación. Decreto por el que se declara de interés público el establecimiento de la zona de protección forestal de la cuenca del Río Tulija, así como de la Reserva Integral de la Biósfera Montes Azules. 12 Enero, México, D.F., Tomo CCCXLVI, No. 9.

1986 Diario Oficial de la Federación. Decreto por el que se declara de interés público el establecimiento de la reserva ecológica de la mariposa monarca. 9 de Octubre, México, D.F.

1992a. Diario Oficial de la Federación. Decreto por el que se declara área natural protegida con el carácter de Area de protección de flora y fauna silvestres la región Chan-Kin, con superficie de 12,184-98-75 hectáreas, ubicada en el Municipio de Ocosingo, Chis. (Segunda Publicación). Lunes 24 de Agosto, 1992. Pp. 16-20,

1992b. Diario Oficial de la Federación. Decreto por el que se declara área natural protegida con el carácter de Monumento Natural, la zona conocida como Bonampak, con superficie de 
4,357-40-00 hectáreas, ubicada en el Municipio de Ocosingo, Chis. (Segunda Publicación). Lunes 24 de Agosto, 1992. Pp. 20-22.

1992c. Diario Oficial de la Federación. Decreto por el que se declara área natural protegida con el carácter de Reserva de la Biósfera la zona conocida como Lacan-Tum, con una superficie de 61,873-96-02.5 hectáreas, ubicada en el Municipio de Ocosingo, Chis. (Segunda Publicación), Lunes 24 de Agosto, 1992. Pp. 22-26.

1992d. Diario Oficial de la Federación. Decreto por el que de declara área natural protegida con el carácter de Monumento Natural a la zona conocida con el nombre de Yaxchilán, con una superficie de 2,621-25-23 hectáreas, ubicada en el Municipio de Ocosingo, Chis. (Segunda Publicación). Lunes 24 de Agosto, 1992. Pp. 27-30.

SEMARNAP

1996 Hacia el Desarrollo Sustentable: Bases de la Transición, Cap. Desarrollo Institucional y Formulación de Políticas, Sinap, $2^{\circ}$ Ed. SEMARNAP, México, D.F.,

1996 México: Hacia el desarrollo sustentable. Bases de la Transición. SEMARNAP, México.

Szekely Miguel y Restrepo Iván.

1988 Frontera Agrícola y Colonización. Centro de Ecodesarrollo. México.

World Bank

1982 Tribal Peoples and Economic Development: Human Ecologic Considerations. Washington, D. C. Estados Unidos.

1990 BID, Estrategias y procedimientos para temas socio-culturales en relación con el medio ambiente. Banco interamericano de Desarrollo, Comité del medio ambiente, Washington, Estados Unidos.

1991 Banco Mundial, Directríz operativa concerniente a los pueblos indígenas. México, D.F. 1992 The World Bank, Enviroment and Development in Latin America and the Caribean: The role of the World Bank. Latin America and Caribbean Region. Washington, D. C. Estados Unidos.

\section{Abstract}

This paper assesses the World Wildlife Fund's project with the Mexican government to create Nature Reserves in four Indigenous communities. It examines the WWF methods for insuring broad participation of local stakeholders-Indian communities, ejidos, and private landowners. While this project's technical aims are clear and precise, the challenge is how to translate them into local discourse so that local stakeholders appropriate them and make part of their everyday actions. These four reserves offer a panorama of the complex social, political, and economic problems that confront this ambitious project.

Key words: Mexico, Conservation, Nature Reserves, Indigenous communities, social impacts, World Wildlife Project, political ecology

\section{Resumen}

Este papel evalúa el proyecto del World Wildfile Fund con el gobierno Mexicano para crear reservas de naturaleza en cuatro comunidades indígenas. Examina los métodos de WWF para asegurar la amplia participación de los sectores locales-comunidades indígenas, ejidos, y terratenientes privados. Mientras que los fines técnicos de este proyecto son claros y precisaos, el desafío es cómo traducirlos a discurso local de modo que los grupos sociales locales se apropien de ellas y los hagan parte de sus acciones diarias. Estas cuatro reservas ofrecen un panorama de los complejos problemas sociales, políticos, y económicos que enfrentan este ambicioso proyecto. 
Palabras claves: México, conservación, reservas ecológicas, comunidades indígenas, impactos sociales, proyecto de la World Wildlife Fund, ecología política.

\section{Résumé}

L'article est une évaluation du projet que World Wildlife Fund (WWF) a entrepris avec le gouvernement mexicain pour créer des réserves naturelles dans quatre communautés indigènes. L'article examine les méthodes de World Wildlife Fund dont le but et d'assurer une participation générale des groupes concernes: Communautés indigènes, ejidos, et les propriétaires privés. Alors que les objectifs techniques du projet sont clairs et précis, le défi réside dans la façon de transformer ces objectifs en un discours local pour que les dépositaires locaux puissent les approprier et les adopter comme partie intégrante de leurs actions. Les quatre réserves offrent un panorama de problèmes complexes aux niveaux social, politique et économique que confrontent ce projet ambitieux.

Mots clés: Mexique, conservation, réserves écolgiue, communautés indígènes, impactes sociaux, protection de la World Wildlife Fund, écologíe polítique. 
El Proyecto del Fondo Mundial para la Protecciôn del Medio Ambiente

This page intentionally left blank 